\title{
DE JOAQUÍN A JACQUES: EL VERDADERO LUGAR DE EDWARDS BELLO EN LA VANGUARDIA EUROPEA
}

\author{
Osvaldo Carvajal M. \\ Universidad Andrés Bello \\ Santiago, Chile \\ osvaldo.carvajal@unab.cl \\ RESUMEN / ABSTRACT
}

En las crónicas, artículos y reseñas que se han escrito sobre Joaquín Edwards Bello (18871968) desde su época hasta hoy, existe una etapa que suele omitirse o, en caso de nombrarse, aparece como una mera especulación o anécdota: su participación en la vanguardia europea. Más allá de algunos ejemplares conservados del poemario ultraísta y dadaísta Metamorfosis (1921), que el autor publicó tras su regreso a Chile bajo el seudónimo Jacques Edwards, no se conocen documentos que prueben que Jacques Edwards haya sido nombrado presidente dadá por el mismísimo Tristan Tzara, como el autor declara en los paratextos del libro. El presente artículo pretende establecer el verdadero rol de Joaquín Edwards Bello/Jacques Edwards en la vanguardia europea, a partir de un exhaustivo trabajo de archivo y reconstrucción de campo cultural en torno a esa etapa casi desconocida de su trayectoria.

Palabras clave: Edwards Bello, vanguardia, dadaísmo, ultraísmo, Vicente Huidobro.

\section{FROM JOAQUIN TO JACQUES: THE REAL PLACE OF EDWARDS BELLO IN THE EUROPEAN AVANT-GARDE}

Among the many chronicles and articles written about the Chilean writer Joaquin Edwards Bello (1887-1968) there is an often neglected reference. When mentioned, it is referred as a rumor or mere speculation. It concerns his involvement in the European avant-garde. The only evidence from his relationship with dadaism is his book Metamorfosis (1921), where he declares that he has been made president of dada by Tristan Tzara himself. This paper pretends to establish the place that Joaquin Edwards Bello/Jacques Edwards really occupied in the European avant-garde.

KEYWORDS: Edwards Bello, avant-garde, dadaism, ultraism, Vicente Huidobro. 
La participación de Joaquín Edwards Bello (1887-1968) en la vanguardia europea y latinoamericana ha pasado a ser una suerte de anécdota que se nombra, de paso y con inseguridad, en muy pocos de los artículos y perfiles que se escribieron y se siguen escribiendo sobre el autor y su obra. Además de una tímida mención al poemario ultraísta y dadaísta Metamorfosis (1921), publicado a su vuelta de una larga estancia en Europa, no existen mayores referencias a ese momento de su trayectoria literaria ni a su alter ego que firmó ese libro: Jacques Edwards. Es más, en sus crónicas -donde solía mencionar los entretelones que habían rodeado la publicación de cada una de sus obras-el autor omite cualquier referencia a Metamorfosis y sus poemas vanguardistas. Este artículo busca establecer el verdadero rol de Joaquín Edwards Bello/Jacques Edwards en la vanguardia europea, a partir de un exhaustivo trabajo de archivo hecho en torno a esa etapa casi desconocida de su trayectoria.

Una de las hipótesis principales de este estudio es que los datos sobre la incorporación del autor al movimiento dadaísta y sus ejercicios escriturales pertenecientes a dicha escuela son relativamente desconocidos porque el autor así lo quiso: en sus materiales conservados hoy en el archivo del escritor de la Biblioteca Nacional de Chile (BN), donde se resguarda la mayor parte de sus manuscritos, no hay ni una sola mención a esta etapa. Tampoco en el archivo que él mismo mantuvo y usó para la redacción de sus miles de crónicas, y que hoy está disponible para su consulta en la sección "Referencias críticas" de la misma BN. Es por esta razón que las fuentes a las que se tuvo que recurrir son mayoritariamente testimonios: correspondencia publicada e inédita de autores del periodo (como el poeta Vicente Huidobro y Andrés Balmaceda Bello, su primo), memorias de críticos españoles de la época (como Rafael Cansinos Assens y Guillermo de Torre) y las mismas revistas en que aparecieron los no pocos textos que Edwards Bello publicó en tierras europeas.

\section{EDWARDS BELLO Y SUS TRES PARÍS: PARAÍSO, PURGATORIO E INFIERNO}

Si bien Edwards Bello atacó siempre, ya fuera de manera directa o indirecta, a su propia clase social, fue determinante para la aparición de sus primeras obras el estatus que le daba pertenecer a una familia de la oligarquía de la época. Según Pierre Bourdieu, aquellos productores que poseen un capital económico abundante tienen cierta libertad con respecto a la dependencia 
material, lo que les permite introducirse en la práctica artística sin la necesidad de tener que realizar tareas secundarias para asegurar la subsistencia (388). Por ello, los autores pertenecientes a las clases dominantes tienden a ir en busca de los puestos más arriesgados del campo cultural, los cuales, a su vez, ofrecen el mayor capital simbólico. En este sentido, no obstante las constantes quejas de Edwards Bello con respecto a la connotación social de su ascendencia, es innegable la importancia que tuvo en su carrera su acomodada posición. Uno de los puntos clave, desde esa perspectiva, es la relación entre su clase social y París, la capital cultural del cambio de siglo. No hace falta decir que la "ciudad luz", a fines del siglo XIX y principios del XX, constituía, para la oligarquía latinoamericana, una Meca ligada directamente a la obtención de estatus social. El viaje iniciático a París significaba la adscripción al estilo de vida moderno. Era la concreción del imaginario folletinesco que permeaba las primeras lecturas de los jóvenes cultos hispanoamericanos, así como el acceso a la moda y las tendencias que definían los modelos que habían de ser seguidos ${ }^{1}$. Por lo demás, en el caso de los escritores en ciernes, era la oportunidad para aproximarse a los grandes maestros y aprender del desarrollo que la modernidad estaba trayendo consigo para la naciente industria cultural. En palabras de Beatriz Colombi, los escritores latinoamericanos que viajaban a las metrópolis europeas

incorporaban rápidamente todos los rituales de la moderna sociabilidad letrada: empresas editoriales, prólogos, siluetas, homenajes, banquetes, salones y el imprescindible café literario. En el comienzo de siglo, frecuentan el ambiente literario de los cafés [...], así como los restaurantes y salones [...] o los cenáculos en Montparnasse (545).

Lo relevante en este caso es que Edwards Bello no hizo solo un viaje a Europa, sino varios. Él mismo, en una de sus crónicas, titulada "Impresiones

En La belle époque chilena, Manuel Vicuña hace una interesante lectura de la importancia que tenía Europa para la alta sociedad chilena del cambio de siglo: "Para la oligarquía chilena, de hecho, las modas francesas e inglesas, y en general los estilos de vida privativos de las clases más encumbradas del Viejo Mundo, representaron las expresiones más legítimas de la civilización moderna [...] Mediante el expediente de la imitación buscaban parecerse a sus modelos, a la par que convertirse en otros sujetos. Dicho sucintamente: vivir como otros para ser, en definitiva, otro" (34). 
de París después de ocho años" y publicada en 1925 en La Nación, señaló: "París en mis recuerdos tiene una fuerza dantesca de paraíso, purgatorio e infierno, así, en el mismo orden que lo anuncio" (Crónicas reunidas I 453). Se refiere el autor, respectivamente, a tres momentos distintos: el de la infancia, el de la adolescencia y el de la adultez.

El primer periodo, asociado con el paraíso, corresponde al "viaje de cultura", como ya se ha dicho, sello de clase de la oligarquía de la época. Habiendo llegado con diecisiete años, esta primera estadía representó para Edwards Bello un acercamiento al estilo de vida del dandi moderno: estuvo de paseo por el Moulin Rouge (Memorias 126), intentó invitar a cenar a la bella Otero, una de las cocottes más famosas de la belle époque (Memorias 172); visitó el Gran Café (Memorias 96) y perdió un manuscrito de novela "a causa del casino" (Memorias 107)2. Todo apunta a que esta primera estadía del autor en Europa "sirvió más que nada para nutrir su enciclopedia, tanto literaria como periodística, y respirar los aires modernos de las metrópolis europeas" (Carvajal, "Nacimiento" 180).

En 1912, año del segundo viaje y que da inicio a la etapa purgatoria, Joaquín Edwards Bello era ya una figura del campo literario nacional: había publicado tres novelas y un libro de crónicas; cada una de esas producciones más polémica que la anterior (Carvajal, "Nacimiento" 191) ${ }^{3}$. Los críticos y sus pares de oficio ya lo conocían y la sociedad lectora de la época había tenido un complejo contacto con sus primeras obras. Dice su primo Andrés Balmaceda Bello que, en esa época, el autor ya había logrado entablar "relaciones literarias" en España y Francia (36). Al mismo tiempo, a sus 26 años, ya se había convertido en un dandi completo: estaba entregado al goce

2 La compilación de crónicas titulada Memorias, de la cual se toman varios aspectos biográficos en este trabajo, fue editada y publicada en 1983 por Alfonso Calderón. En este volumen se incluyen fragmentos de crónicas, apuntes y notas que escribió Edwards Bello a lo largo de su carrera; el eje común es que se refieren a diferentes etapas de su vida. Es por ello que, al disponerlas en orden cronológico el editor, otorgan la ilusión de haber sido redactadas como unas verdaderas memorias.

Su primera novela, El inútil, apareció en 1910. En 1911, Imprenta La Ilustración, de Santiago, puso en circulación Tres meses en Río. Un año más tarde, se suman a su bibliografía las novelas El monstruo y La tragedia del Titanic, ambas por la misma imprenta. El 16 de junio de ese año, apareció el cuento "Una sola sombra larga..." en la revista Musa joven, fundada por Vicente Huidobro y Ángel Cruchaga Santa María. Ese mismo año, dicho relato, al igual que "El billete de banco", aparecería en la compilación Cuentos de todos los colores, publicada por Imprenta Barcelona. 
sensorial de la capital cultural de principios del siglo XX y pasaba sus días dilapidando su fortuna en los casinos.

Hay que decir, eso sí, que, no obstante este estilo de vida, Edwards Bello ya había comenzado a tomar en serio la escritura. En una carta fechada en París, el 2 de agosto de 1913, le cuenta a su amiga María Letelier que está en un "hotelito" de la calle Balzac y que tiene una muy buena vista para escribir: "estoy en el quinto piso no por economía sino porque aquí tan arriba se está más tranquilo y se puede escribir con mayor serenidad" (Epistolario 17). El autor asegura que su cabeza está en sus libros y que prepara su Despertar de Bonaparte, libro que nunca vio la luz y del cual no se tiene ninguna referencia más que su nombre en la carta aludida. Por su parte, haciendo memoria de otro encuentro de esos tiempos, Balmaceda cuenta que su primo estaba imbuido en el trabajo en torno a una próxima novela: "Un cuadro que mostraba la decadencia de nuestros hábitos y virtudes coloniales y del patriotismo [...] El personaje central del libro se llamaba Esmeraldo. Estaba bien elegido. Un emblema nacional de patriotismo, de nobleza, de fuerza y heroísmo $(85)^{4}$.

En general, todo indica que fue durante su segundo viaje a Europa, entre lo que él llamaba sus París de paraíso y purgatorio, que la conciencia de Edwards Bello como escritor profesional fue despertando lentamente. Hasta ese momento, cuesta encontrar una lógica que articule, estéticamente, todos sus ejercicios escriturales. En este mismo sentido, se podría decir que la París del purgatorio operó como una suerte de transición donde la vida de dandi y la de escritor intentaron convivir. Es el siguiente periodo el que representará un verdadero punto de inflexión para su trayectoria literaria.

Una circunstancia determinante en el modo de pensar de Joaquín Edwards Bello fue haber experimentado in situ la Primera Guerra Mundial. Recuerda Balmaceda el estallido del conflicto: "El Gobierno traslada su

\footnotetext{
Aunque podría parecer que Balmaceda se refiere a la novela El roto, que no habría de ser publicada hasta 1920 tras su regreso a Chile, probablemente en realidad está describiendo La cuna de Esmeraldo. Observaciones y orientaciones americanas. Preludio de una novela chilena, libro que apareció en 1918, en París. Comenzado a escribir en 1912 , poco después de que Edwards Bello llegara a Francia, esta obra corresponde a una mezcla genérica: se puede decir que contiene fragmentos de ensayo, crónicas y, finalmente, algunos capítulos de lo que habría de ser más adelante El roto, la novela más exitosa del autor y que se transformaría en su gran proyecto de vida, pues dejaría su última edición corregida antes de suicidarse en 1968.
} 
sede a Burdeos; los extranjeros que no tengan ocupaciones indispensables en París deberán abandonarlo [...] Los Edwards Bello, -toda la familiahabían salido a Londres por ferrocarril, después de un día de espera en la Gare Saint Lazare" (98). El autor de El roto es descrito, en medio de ese panorama, en un estado de éxtasis: la guerra lo exalta y está informado de cada uno de los hechos importantes para el desarrollo del conflicto. En este contexto, señala Balmaceda, Edwards Bello "proporcionaba noticias sobre la guerra y apreciaciones cuyo origen nunca nos dio a conocer. No eran de los diarios ni de las revistas, tal vez de su círculo, siempre incógnito y misterioso. Escribía ahora crónicas para un diario de México que le pagaba bien" (108). Más tarde, estando ambos primos en París, a fines del año 1914, tras un ataque de los zepelines alemanes, cuenta Balmaceda que Edwards Bello tomó un recorte de un diario inglés con la noticia y lo envió a México "con un comentario que los debe haber hecho reír" (117). Agrega que el primo preparaba un viaje a Madrid: "tenía ahí amigos que lo llamaban y su círculo literario lo atraía fuertemente y le decían que sus crónicas podían ser publicadas en el diario A.B.C". A propósito, el autor comentaba: "Tú sabes que el A.B.C es uno de los grandes diarios españoles; colaborar en él significa una consagración periodística y literaria. Además, serán algunos pesos que siempre ayudan" (ibid.). Al otro día, partiría sin que Balmaceda lo volviera a ver, pues regresó a Chile un tiempo después. ¿Qué había pasado con el dandi que andaba de casino en casino por las principales ciudades francesas?

Es evidente que la razón por la que Edwards Bello le asigna a esta etapa de su estadía en París características infernales tiene que ver con las condiciones que generó la guerra, sobre todo la actitud hacia los extranjeros residentes en Francia. Quien hasta ahora había sido un dandi pasa, de un momento a otro, a formar parte de un nuevo grupo: el de los "metecos". Este concepto, métèque en francés, es utilizado en la mayoría de las crónicas que el autor escribió mirando hacia su pasado en la "ciudad luz". En una crónica de 1925, señala que durante la guerra no fue más que un "pobre meteco en la tempestad de denuncias, anónimos, envidias desatadas en torno a los combatientes" (Crónicas reunidas I 453). Hay un punto clave aquí: los que habían sido denominados con la inofensiva, mas despectiva, palabra "rastacueros" pasaban a ser llamados "metecos", gente de la cual sospechar, posibles espías: "gente que comía el pan francés sin utilidad 
alguna para la guerra y que, al contrario, podía entenderse misteriosamente con el enemigo" (ibid.) $)^{5}$.

En 1916, una ley emitida por el gobierno francés mandaba que todo residente en París de ascendencia británica, francesa, italiana, rumana o serbia fuera enviado al frente. En la crónica "Recuerdos de un cuarto de siglo", comenta Edwards Bello: "Yo fui preso como desertor en el Hotel Friedland, llevado a Saint-Denis y enrolado en el $5^{\circ}$ regimiento de zuavos" (Recuerdos 14). A continuación, reconoce que su hermano Emilio, que era cónsul en Liverpool, intervino para salvarlo de la situación. Sin embargo, alcanzó a pasar dos meses en un contexto marcial. Parece ser que esta experiencia tuvo un fuerte impacto en su visión de París, pues en la crónica "El meteco en la guerra", publicada el 14 de noviembre de 1927 en La Nación, reconoce, con frivolidad, sus ganas de ver al kayser marchando por las calles de su ciudad tan querida. Salvador Benadava dice que, en ese ejercicio, "[e]l dandy despechado no solo vuelve la espalda a la amante de ayer sino [que] aspira a convertirse en testigo gozoso de su derrumbe" (143). El espacio que siempre había servido como refugio al autor frente al no sentirse aceptado y querido en su propio país ahora le era hostil.

En este sentido, haber vivido el estallido de la Primera Guerra Mundial y haber sido "expulsado" de su paraíso de infancia determinaron la asunción definitiva del oficio de escritor por parte de Edwards Bello. En casi todo recuerdo que hace el autor de su estancia en París, aparece la circunstancia de la marginalidad identitaria. En la crónica "Memorias y autobiografías", publicada en 1954, se refiere al impacto que tuvo en su conformación como sujeto el conflicto bélico: "Si yo no hubiera vivido en París la guerra 19141918 sería otro. Seguiría creyendo en eso de la aristocracia castellano-vasca y en otras paparruchas por el estilo. Habría un gran vacío en mí. ¡Viva la guerra de 1914!” (Hotel 77). Es tras esas duras experiencias que Edwards Bello decide marcharse a España.

\footnotetext{
Beatriz Colombi señala con respecto a estos términos: "Rastas, rastaquere, metecos, colonos: la extranjería recibió muchos nombres y pocas explicaciones convincentes. Los hispanoamericanos padecían la confusión fomentada por la propia ideología capitalina, entre las familias adineradas que acudían a París para exhibir sus capitales nacidos de la industria de la carne y del cuero, y las más modestas condiciones del sector medio letrado, que convergía igualmente en el mismo espacio en busca de otro tipo de capital" (557).
} 


\section{MADRID: EL NACIMIENTO DE JACQUES EDWARDS Y LA DISPUTA POR UN LUGAR DE AVANZADA EN EL CAMPO}

Para comenzar este apartado, conviene aplicar a Edwards Bello el concepto de "inmigrante de la cultura", utilizado por Juana Martínez para referirse a la diáspora latinoamericana que llegaba a España escapando de la gran guerra y los cambios provocados en París:

muchos artistas e intelectuales se apartan de las zonas en conflicto y eligen Madrid como residencia más segura; es decir, a partir de 1914 empiezan a instalarse en la capital de España algunos de los escritores chilenos que vivirán la vida madrileña de una forma más o menos estable $(73)^{6}$.

En ese sentido, la forma en que el crítico literario Rafael Cansinos Assens narra la llegada de Vicente Huidobro al campo literario madrileño, en 1918, es tremendamente sintomática del momento que atravesaba la literatura española. Entre un poco de vergüenza y algo de admiración, el crítico sevillano recuerda que el chileno "traía las últimas novedades literarias de París" y llevaba para mostrarle unas plaquettes que habían sido publicadas "con arreglo a las nuevas tendencias" en francés (335) 7 . La reacción de Cansinos Assens, quien estaba

6 Por la importancia que tuvo para el ambiente cultural español este momento, Fernando Iwasaki lo ha llamado preboom de la literatura hispanoamericana, pues considera que escritores como el guatemalteco Enrique Gómez Carrillo, el nicaragüense Rubén Darío, el peruano Ventura García Calderón, el chileno Vicente Huidobro y el argentino Jorge Luis Borges, entre muchos otros, llevaron el modernismo y la vanguardia a España: "El preboom enriqueció a la literatura española sin necesidad de transformarla, porque a los clásicos de traje gris no les molestó llevar una flor americana en el ojal de su escritura. En cualquier caso, gracias al preboom la literatura española volvió a mirarse el ombligo y descubrió agradecida que tenía dos" (182).

Probablemente, se refiere a Horizon Carré, aparecido en París en 1917 y publicado por la Imprenta Paul Birault. En esta obra estaban contenidas algunas composiciones que habían sido publicadas en la revista francesa Nord-Sud, dirigida por Pierre Reverdy. De hecho, en el número 1 de la revista Dada, dirigida por Tristan Tzara y publicada en Zúrich, en julio de 1917, se anunciaba la segunda colaboración de Huidobro en el número 3 de Nord-Sud. La primera había sido en el número 2: era el poema “L'Homme triste”. Para un análisis detallado de la participación de Huidobro en la revista Nord-Sud, véase Bary, David, "Vicente Huidobro: el estilo Nord-Sud", en Revista iberoamericana, Pittsburgh, vol. XXVIII, N53, enero-junio de 1962, pp. 87-101. 
en compañía de Guillermo de Torre, evidencia el impacto que provocó la aparición de este joven recién llegado de París en el medio madrileño:

La verdad es que Huidobro nos coge a todos de sorpresa con sus revelaciones y nos descubre un mundo ignorado de inquietud literaria que el telón de la guerra nos había ocultado. No conocíamos a ninguno de esos poetas que Huidobro cita [Apollinaire, Reverdy, Tzara]... Ni siquiera [Gómez] Carrillo, que había llegado de París y siempre fue el cronista de todas las modas literarias, nos había dicho una palabra de las nuevas escuelas... Si no el creador, Huidobro, por lo menos, era el revelador (336).

Ante las revelaciones traídas por Huidobro, Cansinos Assens declara caduco el modernismo y bautiza a la nueva escuela poética como "Ultra": "Un movimiento en el que cabrán todas las tendencias y modalidades con tal que sea nuevas... ¡A Abajo todo lo viejo!” (337). A partir de este momento, el crítico sevillano se convertirá en el conductor teórico-crítico del recién nacido ultraísmo y Guillermo de Torre, mucho más joven, tendrá una doble militancia como poeta y crítico-memorista del grupo. Así, además de la conducción de la tertulia literaria del café El Colonial, en enero de 1919, Cansinos Assens asumirá la dirección de la sección literaria de la revista Cervantes, dándole un giro radical hacia la vanguardia. Ello se anuncia desde el primer número a su cargo, en el cual se publica "ULTRA. Un manifiesto de la juventud literaria", texto sin firma que ha sido atribuido al mismo crítico (Osuna 30).

Volviendo a sus memorias, llama la atención que, tras comentar la conocida polémica entre Huidobro y Pierre Reverdy, Cansinos Assens identifica a Edwards Bello como otro "aspirante" a la paternidad del creacionismo ${ }^{8}$. La forma en que se relata su llegada al café El Colonial, donde el crítico sevillano precedía su tertulia literaria, es digna de ser citada por extenso:

\footnotetext{
Sobre la disputa entre Reverdy y Huidobro con respecto a la anterioridad de las ideas y proyecto estético de cada uno, véase el trabajo de Juana Teruel "La fecha de publicación de El espejo de agua de Vicente Huidobro", en Lexis, vol. II, N 1 , julio de 1978, pp. 71-85. Y también, de Waldo Rojas, "El fechado dudoso de El Espejo de Agua a la luz de la tentativa poética francesa de Vicente Huidobro. ¿Un extravío del anhelo de originalidad radical?”, en Caravelle, $\mathrm{N}^{\circ} 82$, 2004, pp. 63-88.
} 
ahora surge otro aspirante al título en la persona de Joaquín Edwards Bello, un chileno y primo precisamente de Huidobro. Llega al café Edwards con el grupo de jóvenes americanos venidos de París [...] Edwards, que parece el que capitanea el grupo, es un chico simpático, bajito, de grandes ojos negros, lánguidos y cansados, con unas pestañas larguísimas, de vedette, y una elegancia natural que resiste al hongo café con que se cubre, se me presenta como Joaquín Edwards Bello, primo de Huidobro [...] Me habla luego con ironía de su primo Vicente, el fundador del Creacionismo, que ya estaba creado: -Mi primito es un fumiste y un rastaquoère... Usted le ha hecho demasiado caso (Cansinos Assens 338).

Lo más curioso que pretendo mostrar en este apartado, justamente, es la disputa que Edwards Bello y Huidobro sostuvieron en esa época a través de la revista sevillana Grecia.

Habiendo nacido bajo el signo del modernismo imperante en la práctica literaria española de la primera década del siglo XX, Grecia, tras la llegada de Huidobro, dio un giro y se abrió a las nuevas corrientes estéticas venidas de Europa. Y así, a partir de la primavera de 1919, se convirtió en la principal revista difusora de los ultraístas, junto a la ya mentada Cervantes ${ }^{9}$.

En el momento en que Grecia se ha convertido en el eje central de las novedades literarias en España, aparece en el número 33, del 20 de noviembre de 1919, un tal "Jac Edwards". El autor introduce, a través de un artículo titulado “"Galería de Espejos' (Autoversiones del francés)”, algunas composiciones de "Rafael Lasso de la Vega, el joven maestro de poetas, creador y 'pioneer' del versalibrismo castellano, [quien] ha emprendido la traducción de los poemas en francés que integran su sorprendente y originalísimo libro, titulado 'Galerie de glaces', de los cuales se publican algunos a continuación”. Agrega, a continuación, que Lasso "viene a definir con ese libro de novísima poesía, los caminos conceptuales de las modernas

\footnotetext{
En el artículo "Revisión de Grecia en la Vanguardia", José María Barrera López se refiere al giro que dio la revista: "Nacida en el ambiente de la literatura fin de siglo ya gastada, en ese modernismo degradado de donde nace la vanguardia, con un modernismo de simbolismo evangélico y erotizado (versos de Rubén en su frontispicio), poco a poco, la revista se abre a todas las tendencias europeas (Futurismo, Cubismo, Dadaísmo, Expresionismo) y da lugar a esa síntesis innovadora que llamamos el Ultra" (54).
} 
intenciones estéticas, fijando normas y dando la pauta de lo que debe ser el reciente movimiento poético" (“"Galería" 7) ${ }^{10}$.

Ahora bien, aunque pueda parecer que es Edwards Bello quien presenta a Lasso de la Vega a los lectores de Grecia, esto no es así. Desde 1918, antes de que la revista diera su giro hacia la vanguardia, el poeta venía colaborando en ella ${ }^{11}$. En su revisión de las principales revistas de la vanguardia española, Rafael Osuna dice de él que en su formación vanguardista "influyeron sus constantes viajes a las principales ciudades europeas y, en especial, sus relaciones - presumiblemente no todas ciertas- con la vanguardia artística parisina" y que, por otra parte, "Más allá de su periodo vanguardista no

10

Lasso de la Vega es uno de los escritores junto a los cuales se le veía a Edwards Bello frecuentar los cafés literarios madrileños. La primera etapa de su obra da cuenta de la influencia del modernismo en la literatura peninsular de su momento y quedó retratada en libros como Rimas de silencio y soledad (1910) y El corazón iluminado (1919), y en revistas de la época: principalmente, Blanco y Negro y La Esfera. Sin embargo, su orientación estética cambió con la llegada de los jóvenes vanguardistas latinoamericanos. Al respecto, en la entrada que le dedica en Poetas del Novecientos: entre el Modernismo y la Vanguardia: (Antología), José Luis García Martín comenta que Lasso de la Vega se convertirá, en 1919, en uno de los adalides de la vanguardia (21). A su vez, con ironía, Cansinos Assens comenta los proyectos literarios del poeta de la siguiente manera: "Lasso de la Vega, por el trato con Edwards y sus amigos, que vienen de París, ha adquirido pronto el dominio del francés y escribe poemas en ese idioma, estimando que el español es una lengua anquilosada, antipoética" (341). En el medio madrileño, se le acusaba de no tener dominio real de la lengua francesa y de construir sus poemas con palabras sueltas, tomadas de los diccionarios al azar.

11 Su primera colaboración corresponde al poema "Campanas", que apareció el 15 de noviembre de 1918. En una nota al pie del texto, se lee lo siguiente: "Del libro 'Las coronas de mirto' próximo a publicarse" (8). Dicho libro nunca se publicó. El anuncio de libros que posteriormente no fueron publicados es una constante, no solo en las prácticas de Lasso de la Vega, sino también en las de otros escritores ultraístas. Por otra parte, en la introducción a la reproducción de varios poemas pertenecientes a su recién publicado libro El corazón iluminado y otros poemas (que sí existió), en Grecia, el 30 de septiembre de 1919, se anuncia que Lasso de la Vega "va a publicar próximamente la traducción de su libro de poesías francesas, titulado 'Galerie de glaces', hecha por él mismo en versos castellanos" (8). Más tarde, el 12 de octubre, el director de la revista presenta "Tejados", "traducida del caro idioma francés, la más bella composición de "Galería de espejos", obra que "se ha editado recientemente en París y ha obtenido una acogida lisongera [sic] de la crítica, por su inquietud y su modernidad. $\mathrm{Su}$ autor muy pronto la traducirá en castellano, para ofrendarla a los espíritus selectos" (15). Cabe mencionar, desde ya, que el poemario Galerie de glaces jamás existió; sí se publicó en Madrid, en 1942, Galería de espejos, antedatado en "Madrid-París, 1916-1920". Ahora bien, es verdad que Lasso de la Vega solía entregar sus originales en francés: ello se puede apreciar en algunos documentos que están en poder de los herederos de Del Vando-Villar; entre ellos, se encuentra el poema "Toits" ["Tejados"] (González y Reyes 80). 
aportó nada de interés, pasando al silencio literario hasta su muerte" $(62)^{12}$. Cabe preguntarse, entonces, por qué Edwards Bello aparece investido con cierta autoridad, la cual le sirve a Lasso de la Vega como aval de su estatus de poeta de vanguardia. Quizás la respuesta esté en uno de los comentarios que, en la misma introducción, Jac Edwards hace sobre las nuevas ideas poéticas europeas: "Ya el célebre Kostro, -nombre con el que llamábamos sus amigos a Guillermo Apollinaire- proclamaba que la moderna poesía es la eterna y clásica tendida en un arco al porvenir" (7). Y no se contenta tan solo con insinuar una amistad con el célebre poeta francés (conocido en España gracias a Huidobro), sino que además hace referencia a las "revistas más nuevas" de Europa: Dada (dirigida por Tristan Tzara en Zúrich/París entre 1917 y 1921), 391 (dirigida por Francis Picabia en Barcelona/Nueva York/Zúrich/París entre 1917 y 1924) y Littérature (a cargo de Louis Aragon, André Breton y Philippe Soupault en París entre 1919 y 1924), entre otras. Probablemente, es el hecho de haber venido de París el que autoriza a Edwards Bello a aparecer en la emergente vitrina de Grecia como un conocedor de las nuevas tendencias. Tras haber salido apresuradamente, según él, por la "persecución" francesa en 1916, Edwards Bello estaba de vuelta en París en mayo del 1917, justamente el año en que se fundaron algunas de las principales revistas del movimiento dadá. Sin embargo, el autor no ha dejado ningún testimonio sobre sus vivencias como escritor y su relación con el campo literario del París infernal de la guerra. Solo se sabe que, en febrero de 1918, unos meses antes de partir hacia Madrid nuevamente, publicó en Francia La cuna de Esmeraldo, obra que le puede haber servido de carta de presentación a la hora de llegar a su nuevo destino.

Da para pensar que, tras la aparición repentina de Jac Edwards en Grecia, los lectores han de haberse preguntado quién era ese conocedor de revistas francesas que, además, dejaba entrever su cercanía con Apollinaire. El 20 de diciembre del mismo año, en el número 36 de la revista, aparece el poema

12 Cansinos Assens, por su parte, retrata la amistad entre Edwards Bello y Lasso de la Vega en términos de un mecenazgo que ejerce el autor chileno con respecto al español. En sus memorias, el crítico presenta a Lasso como "el poeta helénico", por sus pretensiones academicistas y modos aristocráticos, y lo describe como una cocotte literaria: "Lasso de la Vega siempre cultivó el parasitismo, desde los tiempos de su amistad con [Pedro César] Dominici; siempre anduvo tras los poetas americanos attachés a las embajadas de sus países, medianos y generosos, y nadie como él en este sentido contribuyó a la patriótica tarea de estrechar lazos" (304). 
"París", firmado por "Jacques Edwards" y antecedido por unas líneas con las que Issac del Vando-Villar, director, lo presenta al público:

GRECIA se honra publicando, traducido literalmente del francés, el poema "París", del original poeta chileno Jacques Edwards, aquí casi desconocido -; es de origen irlandés; educado en Inglaterra, pasó después a Francia, donde ha vivido hasta hace año y medio, cuando quedó licenciado por el ejército británico que operaba en el frente francés.

Edwards escribe indistintamente, en castellano, en francés y en inglés. Es primo de nuestro venerado Vicente Huidobro, a quien introdujo y orientó en la moderna lírica, y fue también el íntimo de Guillermo Apollinaire.

En castellano tiene una novela interesantísima: "La Cuna de Esmeraldo" - (París 1913, chez Rosier).

Edwards es un hombre aristocrático, cosmopolita y conocedor del mundo elegante parisién, como puede observarse en su poesía "París", donde pone toda su delicadeza moderna de turista-poeta (12).

El retrato que se presenta, si bien tiene una sólida base de verdad, está tremendamente manipulado ${ }^{13}$. El mismo Huidobro se encargará de aclarar si fue o no el autor de El roto quien lo "orientó en la moderna lírica", como se verá más adelante. Lo que sí se puede afirmar es que esta declaración concuerda con la imagen presentada por Cansinos Assens, según la cual Edwards Bello aspiraba a arrebatarle a su "primo" la "paternidad" del creacionismo.

Sin embargo, en el ámbito privado, no parece que esto fuera así. Hay en el archivo de la Fundación Vicente Huidobro una carta fechada el 27 de diciembre de 1919, en la que Edwards Bello ofrece una explicación al poeta sobre la presentación que se había hecho de él en Grecia:

Mi querido Vicente:

Acabo de tener una muy desagradable sorpresa con esa revista

13 Si bien el autor estudió en Chile en un colegio inglés y pasó unos meses en una escuela británica en 1906, parece un poco exagerado señalar que fue "educado en Inglaterra". Por otro lado, el origen de la familia es inglés, no irlandés (Edwards Bello, Memorias 23). La mención de su anecdótica experiencia marcial pareciera intentar circunscribir definitivamente al autor a un marco de referencia europeo. 
"Grecia" que le mando. Entregué hace tiempo tres poesías a Lasso de la Vega, nada más. Él me leyó un artículo de presentación muy diferente del que aparece ahí. Ahora estoy en cama con fuerte grippe pero inmediatamente he desmentido a Grecia y he mandado a la mierda al intrigante Lasso [...]

Reclamo

Que no soy su primo, sino pariente lejano de Manuelita

Que no conocí a ningún poeta en París hasta que llegó Ud.

Que a mí me interesó siempre más que el mundo intelectual el mundo del juego y los cabarets.

Que Vicente Huidobro ha revolucionado a toda la juventud española dedicada a la lírica.

Haga lo que quiera de esta carta. La he escrito porque es mi deber ("Carta a Vicente Huidobro. 27 de diciembre" s/p).

Como se verá, al parecer esta carta o llegó a destiempo y/o fue ignorada por Huidobro, quien preferirá responder a la afrenta de manera pública. Mientras tanto, el 20 de enero de 1920, en el número 38 de la revista, aparece el poema "El aviador dada", firmado por Jacques Edwards, con una introducción que no tiene firma. Allí se vuelve a subrayar el cosmopolitismo de la formación del autor. Se dice al respecto que es "[c]hileno de nacimiento y francés por su educación" y se apunta a su ascendencia británica por el lado paterno y la relación sanguínea con Andrés Bello por el lado materno. Pareciera ser esta nota biográfica una corrección de la anterior, pues esta vez se habla de "varias obras" en prosa y en verso: "Ha escrito novelas, únicas en su género, describiendo la vida y la sociedad de su país, que le acreditan como el más grande novelista sudamericano. Como poeta pertenece al grupo independiente y libre que presidió su amigo Apollinaire" (5). Esto parece un poco más cercano a la verdad, pues se agregan a su bibliografía sus novelas, pero las hiperbólicas y pretensiosas frases respecto de su prestigio continental no tienen ningún asidero en ese momento. Por último, se cierra la introducción de esta "figura de la literatura moderna" presentando la traducción de uno de sus "caprichos líricos": "L'aviateur Dada" (5). Llama mucho la atención que, bajo el título del poema "El aviador dada", antes del primer verso, a modo de epígrafe, aparezca el mismo primer verso, pero 
en francés: seguramente, para resaltar el hecho de que el original estaba escrito en la tan prestigiosa lengua ${ }^{14}$.

Como se había anunciado, no obstante la creciente presencia de Jacques Edwards en la revista y su intento por aclarar internamente el malentendido con Huidobro, la amistosa carta reproducida más arriba no llegó a tiempo o bien fue ignorada por el destinatario. El 31 de enero de 1920, Grecia venía con una editorial firmada por Del Vando-Villar, titulada "Una carta de Vicente Huidobro". Ante los aspectos biográficos aparecidos en la presentación de Edwards Bello, el poeta chileno se mostraba "sorprendido" por las alusiones a su persona. La misiva estaba fechada en París, el 22 de enero, y pedía la rectificación de tres "falsedades":

\section{El señor Edwards Bello no es primo mío.}

2. El señor Edwards Bello no me ha introducido, ni orientado jamás en la moderna lírica, sino todo lo contrario: yo hice conocer al señor Edwards nuestras tendencias, y muy por encima, pues en las pocas veces que lo vi en París, casi nunca hablamos de arte y cuando algo le dije de mi estética y mis versos, el señor Edwards Bello me decía no entender una palabra $[\ldots]$

3. El señor Edwards no me ha presentado a mí al poeta Guillermo Apollinaire, ni ha sido su amigo íntimo.

Fui yo quien presenté el señor Edwards a Apollinaire una noche en que este último cenaba en mi casa y el señor Edwards llegó de visita cuando estábamos de sobremesa. Esta ha sido la única vez que el señor Edwards ha visto al malogrado poeta [...] Ahora yo me pregunto: ¿De dónde viene ese afán de falsear las cosas? ¿Quién es la persona que les informa a ustedes tan mal? (2).

Las explicaciones que ofrece Del Vando-Villar confirman las declaraciones de Edwards Bello en la carta privada a Huidobro: "Por tratarse de un escritor extranjero extremamos nuestra galantería dando a nuestros lectores algunos de sus pormenores biográficos que, desde Madrid, nos había enviado nuestro colaborador, el poeta Rafael Lasso de la Vega, creyéndolos rigurosamente exactos" (1).

14 El único manuscrito que se conoce de esta época es uno del poema "París", que se conserva en el archivo del escritor de la Biblioteca Nacional de Chile. Está en francés y tiene como epígrafe "publicado en 'Grecia' de Sevilla". 
Efectivamente, había sido Lasso de la Vega el culpable. El 20 de febrero, apareció en el número 40 de Grecia un artículo titulado "La respuesta de Edwards". Venía precedido por una nota del director, quien reafirmaba la culpabilidad de Lasso de la Vega: "En lo sucesivo seremos más cautos y nos guardaremos muchísimo de publicar biografías suscritas por soñadores cuya imaginación hace prodigios confundiendo, como en el caso presente, la realidad con la quimera" (10). La misiva de Edwards Bello estaba fechada en Madrid, el 12 de febrero de 1920 y comienza explicando quién es el culpable del malentendido:

Rafael Lasso de la Vega es el único escritor español que he conocido íntimamente desde que resido en Madrid. Juntos se nos veía siempre en la calle y el café. En los primeros tiempos de nuestra amistad me preguntó si conocía a Vicente Huidobro; le dije que sí, que era primo en segundo grado de su mujer, Manuela Portales Bello, bisnieta de Andrés Bello, como yo. Desde ese día me presentaba en todas partes, diciendo:

-Edwards, primo de Huidobro.

¿Podía yo desmentir una cosa tan inocente que a Lasso agradaba?

Pero creció su interés en presentarme al público como una notabilidad; continuamente me pedía que escribiese para GRECIA y a él debo mi debut explosivo como poeta. Le entregué un poema titulado PARÍS y algunas composiciones humorísticas ("Carta a Vicente Huidobro. 12 de feb." 10).

Agrega que, tras leer el encabezado del artículo, "amonestó" a Lasso y envió un ejemplar de ese número de la revista a Huidobro acompañado de una carta "lamentando ese abuso y achacando toda la culpa a Lasso de la Vega" (ibid.). A continuación, declara que no quiso hacer mal a Lasso acusándolo en público, por lo cual decidió alejarse "de una manera discreta" de él: "Pueden servirme de testigos Rafael Cansinos Assens y Guillermo de Torre. Hace cuatro días recordaba a Cansinos la sorpresa que el párrafo en cuestión me produjo. Yo no fui a París con miras literarias. Nunca busqué la amistad personal con literatos. En la página 238 de La cuna de Esmeraldo (París Librairie Rozier, 26 rue de Richelieu) trato de esto" (Edwards Bello, "Carta a Vicente Huidobro. 12 de feb." 11). Al parecer, Edwards Bello no escogió a los mejores testigos, pues no se ha encontrado ningún registro sobre declaraciones que haya hecho ninguno de los aludidos al respecto. Es más, de las pocas entradas que dedica Cansinos en La novela de un literato a 
Edwards Bello, dos de ellas dan cuenta de que el autor se refería a Huidobro como "primo" y de que pretendía haberse iniciado en la escritura poética vanguardista antes que él.

Nótese, además, la "publicidad" que Edwards Bello aprovecha de hacer de su libro La cuna de Esmeraldo; llama la atención que no aproveche esta ocasión también para corregir la fecha de publicación de la obra, que es el único dato que omite en las nuevas referencias que $\mathrm{da}^{15}$. Con respecto a su obra anterior, la carta se cierra de la siguiente manera:

Para terminar, diré que mi oficio es hacer novelas. De vez en cuando ensayo caprichos líricos a manera de experiencias estéticas o de simple entretenimiento. Soy el novelista más popular y discutido de mi tierra. El Inútil, ensayo de mi primera juventud, alcanzó seis ediciones: Tres meses en Rio, donde describo la revolución de Joao Cándido de manera humorística, me cerró las puertas del Brasil por orden del barón de Rio Branco (ibid.).

Los avatares de la vida como inmigrante latinoamericano en Europa parecen haber reafirmado la vocación literaria del autor y haberlo hecho madurar en cuanto a su forma de plantearse el oficio de escritor. Cabe destacar, a su vez, la utilización y especulación que lleva a cabo el autor a partir de sus primeras novelas publicadas en Chile y su recepción. Esta noción de superioridad respecto a los demás novelistas de Chile se verá también refrendada en el ámbito privado.

Véase otra carta que, un día después de redactar la recién citada, Edwards Bello escribió a Huidobro. Esta vez, el tono es mucho menos amistoso:

15 Sí se toma el tiempo, en cambio, para rectificar y explicar aquello de su paso por el ejército británico. Por otro lado, en la página de La cuna de Esmeraldo a la que hace referencia Edwards Bello, sobre la costumbre de rodearse de otros autores para aprovecharse de su renombre, se lee: "El autor literario, sin dignidad, ansía elevarse sobre todos sus rivales por sus relaciones con literatos [...] El escritor mediocre americano en Europa es como esos señores pegajosos que se cuelan donde menos se les espera; el que viaja con balumbas de artículos es temible. Cuando muere un genio sale siempre un americano recordando cositas que le dijo y contando anécdotas de cuando tomaban el café juntos. En muchas capitales de América los cenáculos literarios poseen listas sebosas con los domicilios de todos los genios de Paris, Madrid y Roma. Me consta que ganaríamos mucho quemando esas listas" (238). 
Cuando apareció el párrafo lleno de falsedades en GRECIA le escribí una carta leal y sincera $[\ldots]$ explicando lo ocurrido. ¿Recibió esa carta? [...]

¿Tenía Ud. interés en rebajarme? ¿Cree Ud. que puede ganar mucho peleándose conmigo? Está bien que Ud. desmienta las falsedades que no sé con qué intenciones se dijeron, pero no debió herirme porque obraba en su poder una carta mía acusando al autor de tales falsedades $[\ldots]$

¿No comprendía yo nada de su estética?

¡Vamos! ¡Sea justo! Todo aquel que está en un plan superior, aunque no sea más que por una fatalidad de su destino, es ironista y el ironista empieza por reírse de sí mismo. ¿Cómo voy a negar que me da risa, una risa nerviosa, el triunfo de esta literatura nueva, un poco Charlot, que va a revolucionar al gros y epais burgeois? [...]

Voy a poner aquí algunos datos interesantes que pude poner en la carta que mandé a Sevilla para su publicación en GRECIA. No quise hacerlo. Inmediatamente que Ud. llegó a París preguntó por mí en la Legación, donde no sabían nada. Fue a verme con gran cariño.

¿Fue por egoísmo, para que yo le buscase casa, etc.?... -No creo.

Un día se puso a escribir cada palabra con su color, poniendo encima de la mesa una cajita de lápices. Yo dije que no entendía una palabra. ¿Era eso su estética? [...]

A la comida que Ud. dio a Apollinaire asistí no de sobremesa sino como comensal. No desmiento esto porque no tiene importancia (Edwards Bello, "Carta a Vicente Huidobro. 13 de feb." s/p).

Años más tarde, en mayo de 1922, estando en Madrid (tras haber regresado por dos años a Chile), Edwards Bello escribió una carta a Huidobro, quien se encontraba en París, con la intención de poner fin a sus viejas disputas:

Yo le defiendo a Ud. y me he puesto a su lado en rango cerrado porque creo que defenderlo a Ud., a pesar de la distancia que va de uno a otro en ideal estético y todo, tenemos puntos de parecido en la envidia que nos tiene cierto elemento castrado. No pueden comprender allá que personas independientes y ricas, desligadas del montón, hagan labor aparte, fuera del rebaño. El rebaño huele mal dijo Dermée.

Nosotros tuvimos un malentendu, pero espero que ahora seamos amigos. ¿No se hicieron la guerra Alemania y Rusia? Firmemos ahora el acuerdo de Rapallo. Mándeme material para hacer un largo estudio sobre su labor, sob. [sic] sus triunfos. 
Yo le admiro ahora. Sé que Ud. tiene defectos de carácter, pero su obra está por encima de ellos. Yo paso su egolatría.

Siento que Chile no haya ayudado al prestigio de su joven creador, su gran lírico ("Carta a Vicente Huidobro. Mayo de 1922” s/p).

En cierto modo, esa tardía carta cierra el episodio buscando estrechar lazos entre dos artistas pertenecientes a la misma clase social privilegiada, la oligarquía chilena, que ya en este momento han encontrado cada uno su espacio de avanzada en el campo cultural, por lo que ya no es necesario competir: Huidobro, en la poesía; Edwards Bello, en la novela. El primero había ganado no una, sino dos batallas por la paternidad del creacionismo apoyado por la revista Grecia (contra Reverdy y contra Edwards Bello). Además, su anhelado proyecto Creación. Revista Internacional de Arte (Madrid/París) había visto la luz y se había instalado como un reputado conferencista y poeta en el marco de la vanguardia francesa ${ }^{16}$. Por otro lado, Edwards Bello vuelve a Madrid tras haber publicado en Chile su novela más importante, El roto (1920), un éxito de ventas y de circulación masiva, algo impensado para la época (Carvajal "Historia" 34-36); y Metamorfosis (1921), poemario dadaísta que recogía sus textos publicados en las revistas vanguardistas de Madrid y París, que se revisarán en el siguiente apartado.

Como podía esperarse, la disputa con Huidobro tuvo como efecto que el nombre del autor del poema "París" se hiciera aún más conocido: el 29 de febrero de ese mismo año, en el número 41, el escritor gallego Eugenio Montes dedicaba su poema "Gavilla lírica" a Jacques Edwards (Montes 12). Es más, después de la polémica, en Grecia continuaron apareciendo los "caprichos líricos" del autor. En 1920, la revista había cambiado su sede de Sevilla a Madrid, ubicándose desde la capital y asumiendo su lugar como medio de difusión principal del ultraísmo. En el número 43, del 1 de junio, aparece publicada una prosa poética titulada "Dios - $\mathrm{N}^{\circ} 1.000$ calle Pot de fer", firmada por Jacques Edwards. Es un texto provocador en el que el hablante lírico cuenta lo que transcurre en el último día del mundo: se toma un café y discute con el "tonto y cursi" Dios en el bulevar y, luego de que se ha postergado el apocalipsis, sale a caminar con la deidad rumbo al prostíbulo

16 En diciembre de 1921, Huidobro dictó su famosa conferencia "La Poesía", que sería posteriormente el prólogo de la edición española de Temblor de cielo. Apareció también ese mismo año, en París, Saisons Choisies, una antología de sus poemas. 
La Gloria, donde el todopoderoso era conocido, pues la encargada lo saludó diciendo "¡Le bon Dieu!" (15)

En el siguiente número, publicado el 15 de junio, en el contexto de una "Pequeña antología moderna", junto a un poema de "Rapháël Lasso de la Vega", aparece "El gato muy gordo", de Jacques Edwards ${ }^{18}$. Ha vuelto, en esta ocasión, la costumbre de poner, a modo de epígrafe, el primer verso en francés y, probablemente, tiene la misma función: en la selección, hay textos de Francis Picabia y de Jean Cocteau; por tanto, se da a entender que los cuatro han debido ser traducidos del francés. Si antes se podía haber pensado que este era un uso que Lasso de la Vega pudo haber recomendado a Edwards Bello, el hecho de que aparezca en todos los poemas de la antología, considerando además que Edwards Bello declaró públicamente haberse alejado de su amigo "mistificador", podría indicar que corresponde a una decisión editorial de la revista más que a la voluntad de los autores. Sin embargo, en los textos que siguió publicando Lasso de la Vega tras la desaparición de la revista Grecia, en Ultra de Madrid, a partir de 1921, se utiliza el mismo recurso solamente en sus textos ${ }^{19}$.

El último texto que publica Jacques Edwards en Grecia apareció en el número 45, del 1 de julio de 1920. Es, nuevamente, una prosa poética y se titula "La guerra" y lleva el epígrafe "Notas de un 'meteque". Por supuesto, el texto se refiere, en clave dadaísta, a las condiciones y pesares que hubo de vivir durante la guerra en París: "Todos los extranjeros son espías. ¡Cochino neutro! Mi ficha pesa tres kilos y medio en la comisaría del quinto distrito" (4).

Ad portas del retorno a Chile, Edwards Bello se ha creado un nombre como poeta de la vanguardia española. Ese mismo año en agosto, en el número 3 de la revista La Pluma, se publicó una reseña titulada "Grecia. Revista decenal de literatura.- Director: Isaac del Vando-Villar.-Madrid" que, desde un punto de vista crítico, señalaba lo importante que había sido la revista Grecia para

17 Cabe señalar que el nombre del prostíbulo usado por Edwards Bello es el de las escenas narradas en la segunda parte de La cuna de Esmeraldo y será el mismo que aparecerá ese mismo año en El roto, tras su llegada a Chile.

18 El texto de Lasso de la Vega, quien ha escogido una ortografía muy particular para escribir su nombre, se llama "Rosa de los vientos".

19 Lasso publicó en Ultra traducciones y textos suyos (incluso, en el número 12, año I, aparece publicado un poema perteneciente al inexistente Galerie de glaces, esta vez fechado en 1917). En todos los poemas, el primer verso está en francés a modo de epígrafe. 
el ultraísmo hasta el momento. En el artículo, el nombre de Edwards Bello aparece entre los destacados:

No todos los humoristas líricos de Grecia solicitan por igual nuestra atención. Gerardo Diego, Adriano del Valle, la grabadora en madera Norah Borges, y especialmente Jacques Edwards nos parecen dotados de cierta personalidad, difícil de destacar entre las estrechísimas reglas de la nueva estética. Bienvenida sea Grecia, juvenil vanguardia de batalla que compartimos contra las fósiles fortalezas en que adolece nuestra literatura contemporánea ("Grecia” 144).

Meses después, en septiembre de 1920, en Grecia, específicamente en la sección de Guillermo de Torre "Álbum de retratos de París y Madrid. Mis amigos y yo" (que se extendió entre los números 45 y 48 de la revista), el autor aparece descrito de la siguiente manera:

Joaquín Edwards: Jovial, caudaloso de juventud y lleno de irónico humor, ha encontrado en DADA la fémina deseada, su amiga más afín, sensual y fidelísima, que no le engañará jamás, sonreirá siempre junto a él y será un elemento decorativo y placentero en su vida mundana, más incomparablemente grato que el whisky, la ruleta o las horizontales lujosas y succionantes (12).

El listado de amigos del crítico incluye, entre otros, a actores del campo cultural español como Teresa Wilms Montt, Norah Borges, Del Vando-Villar, Gerardo Diego, Cansinos Assens, Huidobro y Ramón Gómez de la Serna. Por otro lado, están también las principales figuras de la vanguardia parisina: Tristan Tzara, Francis Picabia, Max Jacob y Paul Dermée.

Ahora bien, no obstante ese gesto de reconocimiento, a la hora de escribir la historia del movimiento, tanto en los mismos años de la vanguardia como posteriormente, De Torre tiende a reducir la importancia de Jacques Edwards. En noviembre de 1920, en el número 23 de Cosmópolis, apareció un largo estudio suyo titulado "El movimiento ultraísta español" en la sección "Literaturas Novísimas". Allí, además, de excluirlo de la antología de poetas ultraístas que presenta (la cual incluye desde Gerardo Diego hasta Lasso de la Vega), lo reduce a uno más de los "escritores que desde el primer momento se manifestaron simpatizantes de las normas ultráicas" (De Torre, "El movimiento" 493). Más tarde, en 1925, en su precoz Literaturas europeas de vanguardia, ante el ejercicio de reconstruir como cronista y a la 
vez partícipe de los hechos el movimiento vanguardista europeo, se detiene sobre el amigo chileno tan solo en una línea para describirlo como el "sutil, irónico y cosmopolita, autor de Metamorfosis", entre otros varios "poetas de más indecisa personalidad, que no pueden considerarse como genuina y originalmente ultraístas, mas que, sin embargo, han experimentado el embate de este movimiento" (De Torre, Literaturas 106). Finalmente, ya consagrado como crítico y vestido con una impronta más académica, hacia el final de su vida, cuando publica su monumental Historia de las literaturas de vanguardia (1965), nuevamente aparecen nombrados en una sola línea de la obra Edwards y su Metamorfosis (1921); este último, como uno de los pocos "testimonios ultraístas en páginas encuadernadas" (De Torre, Historia 554) ${ }^{20}$.

La última mención del autor en el marco del movimiento ultraísta se encuentra en el primer y único número, de diciembre de 1920, de la revista Reflector, cuyo secretario de redacción era Guillermo de Torre. Allí, en un listado titulado "Algunos de nuestros colaboradores", que incluía a autores como Aragon, Borges, Breton, Dermée, Gómez de la Serna, Picabia, Tzara y Del Vando-Villar, aparece "Joaquín Edwards". La colaboración de Edwards Bello, es evidente, quedó solo en la promesa.

El movimiento ultraísta seguiría unos años más, extendiendo incluso su participación al contexto europeo. La revista Grecia, sin embargo, dejaría de publicarse tras el número 50, en noviembre de 1920. A partir de entonces, Ultra, de Madrid, pasaría a ser la plataforma principal de publicación de los ultraístas ${ }^{21}$.

20 Cabe agregar, además, que uno de los poemas del libro Hélices (1923), de De Torre, estaba dedicado a Jacques Edwards.

$21 \quad$ En el artículo "El ultraísmo español en las revistas de la primera vanguardia belga: poesía y grabado en madera (Amberes-Bruselas, 1920-1922)", Emilio Quintana evidencia que, en 1921, Raphaël Lasso De la Vega fue nombrado "representante regional en España" de la revista Lumière, de Amberes (s/p). El contacto se había logrado a través de Ultra, de Madrid. Además, publicó en esa revista dos poemas en francés, el 1 y 15 de septiembre de ese año: "Promenade" y "Absence", respectivamente. Cabe mencionar que, en esta misma revista, el 15 de febrero de 1922, apareció el poema "Cabaret", de Guillermo de Torre. Lo interesante del caso es que, en la revista Vltra de Oviedo, se había publicado el 15 de diciembre de 1919, con una dedicatoria a Blaise Cendrars, el poema "Jazz-band", que parece ser una versión previa de "Cabaret". En una nota aparecida junto con "Jazz-band", se leía: "Poema traducido directamente por su autor del libro en preparación Beautés d'aujourd d'hui" (Cit. en Quintana s/p). Como ha sido la tónica con los ultraístas revisados, ese libro nunca se publicó. Concluye Quintana al respecto: "Mi impresión, por tanto, es que los poemas que Lasso de la Vega y Guillermo de Torre publican en la revista belga Lumière no son traducciones, sino 


\section{JACQUES EDWARDS: ¿PRESIDENTE DADÁ?}

Como se dijo al comienzo de este texto, el único antecedente concreto que se tenía de la participación de Edwards Bello en la vanguardia europea son los paratextos de su poemario Metamorfosis, publicado en Santiago en 1921. El autor firma allí como "JACQUES EDWARDS, proclamado presidente DADÁ por Tristan Tzara en la proclamación universal de presidentes en el Salón des Independants, París 1919" y anuncia: "Este folleto contiene composiciones ultraístas y dadaístas" (8). Cabe preguntarse, a partir de ello, qué hay de verdad en la firma y el anuncio.

Efectivamente, la ceremonia de nombramiento de los presidentes dadá se realizó, pero no en 1919, sino un año después, por lo que Edwards Bello no pudo estar presente, ya que en esas fechas se encontraba en Madrid. Los primeros días de febrero, se publicó en París el número 6 de la revista $D A D A$, en formato de bulletin. Este contenía el programa de la "Matinée du Mouvement Dada le 5 février 1920", que se celebraría en el Salon des Indépendants, del Grand Palais des Champs Elysées. Según el boletín, de cuatro páginas de extensión, en la ocasión se leerían, a varias voces, manifiestos de Francis Picabia, André Breton, Paul Dermée y Tristan Tzara, entre otros ${ }^{22}$. La segunda página, que incorpora un breve manifiesto de Picabia, reza en la parte inferior derecha: "Vivent les concubines et les concubistes. Tous les membres du Mouvement DADA sont présidents" (2).

Al dar vuelta la página, se encuentra una lista de "Quelques Présidents et Présidentes". Entre ellos, hay varios nombres con los que se ha trabajado en este estudio, algunos de los cuales han sido afrancesados: "Cansino d'Assens",

textos escritos en francés, pertenecientes a libros en proyecto que nunca vieron la luz, quizá como parte de una imprecisa expansión internacional del Ultra a través de la lengua poética por excelencia de la vanguardia" (s/p).

22 Rivas Cherif ofrece, en un artículo en El Sol de Madrid del 2 de marzo de 1920, un breve relato de lo que efectivamente pasó en la velada: "Tristan Tzara, iniciador del movimiento, se presentó al público en la conocida actitud del conferenciante: tras una mesa soporte de un vaso de agua, y cuartillas en mano; mas apenas se sentó y a tiempo de comenzar su lectura, desatóse [sic] entre bastidores de la escena donde la sesión se verificaba tan formidable campanilleo, que no llegaron a oídos del público sino unas cuantas palabras del discurso incoherente del director de 'Dadá'; otro poeta, desconocido de los oyentes, salió a leer versos con antifaz y el apologista de las varias pinturas y dibujos modernos que nos fueron asimismo mostrados borró la última obra de uno de los expositores, livianamente trazada con tiza en un encerado" (Cit. en Sarmiento 44-45). 
"Vincente [sic] Huidobro", Guillermo de Torre, Lasso de la Vega y Jacques Edwards. La inclusión del autor en esta lista sirve a este estudio para constatar que Edwards Bello era efectivamente presidente dadá: al igual que los otros 76 nombres que componen la lista.

Ahora bien, la confirmación de que Edwards Bello no estuvo presente en dicha ceremonia se obtiene al mirar la contraportada del Boletín, en la cual aparece reproducido un telegrama del autor:

MADRID: "Je suis au courant de la révolution lyrique DADA par Huidobro, Guillermo de Torre, Cansinos d'Assens, Lasso de la Vega, etc. Toute la jeunesse intellectuelle de Madrid et du Chili se joint petit à petit à ce mouvement immense"

Adios Señor Jacques Edwards

Llama la atención que, de los cinco presidentes dadá que han aparecido en este estudio, solo dos hayan publicado en $D A D A$ : Jacques Edwards y Vicente Huidobro ${ }^{23}$. Lasso de la Vega, De Torre y Cansinos Assens solo son nombrados. Llama aún más la atención constatar que, en apariencia, los únicos contentos con el nombramiento son Edwards Bello, que llegará ostentando y antedatando el flamante título a su regreso a Chile, y Lasso de la Vega, quien en las memorias de Cansinos Assens figura haciendo gala del título ${ }^{24}$. De hecho, en su Diccionario de las vanguardias españolas, Juan Manuel Bonet dice que de "todos los 'présidents Dada' designados por [Tzara] en 1920, [Edwards] fue, que sepamos, el único que hizo figurar ese cargo bajo su firma" (14).

23 En el número 3, publicado en Zúrich en diciembre de 1918, apareció en la contraportada el poema "Cow-Boy", firmado por "Vincente Huidobro". Por otro lado, en el número 12 de Littèrature, de febrero de 1920, se anuncia que "L'abondance des matières et le peu de place dont nous disposons nous contraignent de renoncer à leur publication des réponses" de treinta autores; entre ellos, el español Guillermo de Torre (30).

$24 \quad$ Ante los ataques del medio literario de no conocer realmente la lengua francesa ni entender la nueva estética, Lasso de la Vega responde en código vanguardista: "Ese es el poema dadá... Yo soy presidente Dadá... Dadá es la liberación... Alegría de ser poeta Dadá" (Cansinos Assens 341). 
Un mes más tarde, ya "nombrado" presidente, en marzo del mismo año, apareció un breve poema firmado por Jacques Edwards en el número 7 de $D A D A$ :

Déconcertons
troublons
énervons

Charlot

partout

guerre à l'amidon. $(5)^{25}$

Por otro lado, en abril de 1920, en el primer número de la revista Cannibale, al pie de una página ocupada casi plenamente por un texto de Tzara, apareció el siguiente anuncio de una revista que jamás existió: "Guillermo de Torre et Jacques Edwards ont fondé a Madrid une revue dadaïste: "Vertical". Nous espérons que'elle apportera un peu de clarté dans le chaos romántico-picturalespagnol-littéraire" (s/p). Es interesante considerar que, al igual que los demás documentos que se han revisado que vinculan a Edwards Bello con Tzara, este anuncio se genera a partir de una comunicación a distancia entre ambos escritores: pareciera ser que no llegaron a conocerse personalmente ${ }^{26}$.

25 Este mismo poema había sido publicado en español el 15 de junio de 1920, en el mismo número de Grecia en que apareció "El gato muy gordo", en el marco de una compilación de poemas breves y frases dadaístas titulada "DADA. Sociedad Anónima para la explotación del vocabulario": "Enervemos, deconcertemos, turbemos. / Charlot 'Nihilismo de la risa'. / J. Edwards" (5).

26 Resulta que De Torre le había escrito el 25 de marzo a Tzara contándole de la gran velada "Vertical" al estilo dadá que se realizaría en la Academia de la Lengua de Madrid:

Cher reggiseur Tr. Tzara:

Tout Madrid devient hiper-dadaiste [...]

Nous projetons -Edwards et moi- avec deux amies, nouvelles dadaistes, Thérese Wilms, poetesse, et Norah Borges [...] un voyage prochaine aux royaunes de DADA (Cit. en Le Bon 635).

Es claro, tanto por el estilo de la misiva (en el vocativo se refiere a Tzara como "querido gerente/administrador") como por el hecho de que el viaje jamás se concretó, que el desplazamiento al que se refiere De Torre es simbólico, estético: en este comunicado el crítico no solo declara su adhesión a dadá, sino que hace partícipe también del movimiento a Teresa Wilms Montt y Norah Borges, poeta y grabadista respectivamente, quienes colaboraban regularmente en Grecia. 
Volviendo a Metamorfosis, es curiosa la antedatación que hace Edwards Bello de la ceremonia en el paratexto, al señalar que fue en 1919 en vez de 1920. Claramente, su intención es hacer parecer que estuvo allí. Ahora bien, como se ha visto, el autor no miente al decir que es, efectivamente, presidente dadá. Y no solo eso: tampoco miente al sostener que mantiene comunicación por correspondencia con su "jefe", "el inventor de la lengua francesa", Tristan Tzara:

\section{Monsieur Tristan Tzara}

Cher president

J'ai l'honneur de comuniquer a votre excellence que le Nicaragua, le Guatemala et le Perou on reconnue la republique DADA. On a pavoise.

Esta breve carta, sin fecha, se conserva en el Fondo Tristan Tzara de la Biblioteca literaria Jacques Doucet, en Francia ${ }^{27}$. Allí mismo, hay otra que tiene por fecha de envío el 6 de marzo de 1920, un mes después de la primera matinée dadá:

\section{T Tzara}

Paris

Cher president

Veuillez m'envoyer deux examplaires du fenomenaux bulletin DADA $\mathrm{N}^{\circ} 6$ publié a l'ocasión de la presentation de la Republique DADA a Ms Poincaré.

Estos textos, que Tzara guardó, dan cuenta de una relación epistolar que hasta el día de hoy había permanecido en el campo de la mitología. Alfonso Calderón, el mayor compilador de las crónicas de Edwards Bello, en una entrevista hecha por Salvador Benadava, cuenta que el autor le mostró alguna vez, junto a otras epístolas de célebres escritores españoles, la carta en que Tristan Tzara lo investía con el cargo. Sin embargo, informa al Huidobro, las vanguardias y el dadaísmo, quien me permitió el acceso a estos documentos. Agradezco también al Dr. Timothy Shipe, curador del International Dada Archive de la University of Iowa, quien me dio acceso a una primera versión de estos y más materiales que se encontraban en el catálogo de la exposición $D A D A$, del Centre Pompidou y la National Gallery of Art de Washington. 
entrevistador que la mayoría de esa correspondencia se ha dispersado y está perdida (Benadava 274). Es imposible saber si a lo que se refería Benadava era propiamente una carta o uno de los ejemplares del bulletin al que se ha hecho alusión más arriba.

Finalmente, el último texto de corte dadaísta de Jacques Edwards que fue publicado en Europa es "Espiral", que apareció el 15 de noviembre de 1921, en el número 1 de Tableros, revista también dirigida por Isaac del Vando-Villar, que intentó ser una continuación de Grecia, pero que duró tan solo cuatro números.

\section{CONCLUSIONES}

Es un hecho que el gran cambio en cómo Edwards Bello se veía a sí mismo con relación a la escritura se produjo en Europa. Es, tal y como se revisó, la París paradisíaca la que le da las primeras pinceladas de dandi: lo viste con ropas galantes y le otorga una cultura cosmopolita que hace que, en su regreso a Chile, sea envidiado y resalte entre la multitud de no iniciados en el secreto de la "ciudad luz". Definitivamente, el haber pasado por la experiencia de haber sido "nadie" en Europa genera un fuerte contraste con la notoriedad que ganaban los recién llegados del viejo continente en la capital santiaguina. Según Mónica Bernabé,

Arremetiendo contra la uniformidad impuesta por la vida burguesa, los cultores del dandismo se dedican a argumentar y a exhibir una práctica de vida diferente. La práctica dandy se vuelve facciosa cuando rechaza los valores imperantes desde los inicios del capitalismo: utilidad, dinero, progreso, velocidad (25).

Edwards Bello es un dandi que se contradice: afirma querer que lo dejen tranquilo, pero no pierde oportunidad para lucir su postura desafiante frente al mismo círculo del cual desea alejarse. Sus novelas y la reacción que causan en el público así lo demuestran.

Más adelante, durante su estancia purgatoria, será cuando nazca Jacques Edwards. Así al menos lo evidencia el relato que traza Balmaceda, al decir que sus conocidos lo llamaban "Jacques". Sin embargo, este afrancesamiento de Joaquín y su "metamorfosis" en Jacques también en este marco es 
contradictorio con lo que él mismo critica en sus crónicas de La cuna de Esmeraldo, que fueron escritas en esa época:

El indo-mediterráneo de América se extranjeriza de la manera más deplorable: los viajes y las lecturas ultramarinas lo macaquizan, lo hacen antipatriota y blasé no se adapta con serenidad á la cultura europea [...] La cultura de Europa es un espejo convexo para él: se contempla y se siente achatado, aplastado, empequeñecido por su origen. Todo el afán del que vive más de tres años en Europa es parecer europeo (Edwards Bello, La cuna 11).

Todo indica que, irónicamente, él no se siente parte del grupo de afrancesados al que tanto critica ${ }^{28}$. En este marco, sin duda, el evento que dividió su relación con París en un antes y un después fue el estallido de la Primera Guerra Mundial. Este proceso se dio en dos planos: en el personalidentitario y en el escritural. Hay que subrayar la ironía de que la que él considera su peor época en París sea definitoria con respecto a su vocación y práctica literarias. Una vez más, el (no)lugar que ocupa como extranjero en Europa lo lleva a intentar insertarse de algún modo; para ello, se postula aquí, nace Jacques Edwards, poeta, en España.

Si el París de la Primera Guerra fue donde Jacques Edwards nació, en el Madrid ultraísta fue donde se hizo poeta, donde cultivó un género que Joaquín Edwards Bello no habría practicado. Aníbal González anota que el chroniqueur "de oficio" cambiaba su seudónimo y estilo para trabajar en distintos medios de prensa a la vez (32). En este caso, Edwards Bello lo utiliza para dar rienda suelta a sus delirios poéticos influidos por el movimiento dadá, lo que le permitió integrarse de manera exitosa a la vida madrileña de cafés y tertulias literarias. Incluso, hizo uso de estrategias que parecen haber sido costumbre entre los escritores de la vanguardia española, como la especulación bibliográfica y la autotraducción. Por eso mismo, su primera aparición fue retratada en forma caricaturesca por Cansinos Assens, pero los vínculos que creó en esos años tuvieron frutos en viajes posteriores a 
la capital española ${ }^{29}$. Tras volver en 1922, será parte del "Banquete a Don Nadie", organizado y presidido por Gómez de la Serna en el Café y Botillería Pombo y, posteriormente, en 1925, durante su estadía diplomática, publicará varias obras ${ }^{30}$.

Ahora bien, tomando como hito el regreso a Chile del autor tras todo su periplo vanguardista, cabe hacerse una pregunta. El proyecto escritural que enunció Edwards Bello en La cuna de Esmeraldo hablaba de claridad y "hablar en americano" como el gran fin de la literatura del continente (2). ¿Cómo entender, entonces, la publicación de Metamorfosis en 1921? ¿Cómo explicar, además, que intentara esconder, posteriormente, esa etapa de su obra el mismo autor? Salvador Benadava, ante el gesto vanguardista de Edwards Bello en Chile, se muestra "perplejo", pues "toda su producción literaria se encuentra en las antípodas de estos movimientos" (133). Plantea, intentando darle algún sentido, que la publicación del libro en 1921 podría entenderse como una "tentativa fallida de rivalizar con Huidobro (o de ridiculizarlo)" (ibid.). Más que ridiculizar, Edwards Bello, en un primer momento, efectivamente busca competir con Huidobro: ya se ha dicho que son dos escritores privilegiados disputándose una posición de avanzada en el campo. Justamente por eso hace tanto sentido que en 1922 el autor, después de haber descubierto en la práctica que podía llegar a ser "el novelista de su tierra" (tras el éxito rotundo de ventas que fue El roto), decide buscar la amistad del poeta, pues comprende que su lugar en el campo no es el mismo, por lo que la competencia ya no es necesaria. El autor, tras su periplo por

29 Juana Martínez señala que, en 1928, tras la aparición de la novela El chileno en Madrid, Cansinos Assens "modifica [...] la actitud irónica que había mantenido hacia Edwards con anterioridad, mostrando un sincero reconocimiento hacia esta novela cuyo argumento considera 'universalmente humano' y situándola entre las que mejor habían sabido arrancar la 'viva palpitación' del 'corazón del pueblo"” (84).

$30 \quad$ Agrega, al respecto, Martínez: "En el terreno editorial, el camino abierto pocos años antes se ensancha con la publicación de tres libros que introducen a los españoles en distintas cuestiones de índole política y sociológica sobre la realidad chilena y americana en general. En el mismo año de su llegada, los editores madrileños Hernando y Galo Sáez sacan a la luz El nacionalismo continental. Crónicas chilenas, que mereció un detenido comentario de Luis Araquistáin, uno de los pilares del periodismo de la época y famoso novelista y ensayista político, que también frecuentaba las tertulias literarias a las que asistía Edwards. Un año después, los mismos editores publican Tacna y Arica; Balmaceda-Alessandri. La tierra de Patiño. Cap Polonio, y Ediciones Auriga, también en Madrid, saca otra recopilación similar con el título Tacna y Arica; Cap Polonio. Esta magnífica recepción le lleva a reconocer poco después que su experiencia en Madrid como escritor había sido muy satisfactoria" (81). 
Europa, ha comprendido cómo opera el campo cultural y tiene claridad de las estrategias que le permitirán reinsertarse en el campo chileno.

Respecto a su rol en el movimiento dadaísta, lo que aporta esta investigación es la demostración de la preexistencia de la mayoría de los textos de Metamorfosis (el único original del libro es "Aquel maldito tango") y la comprobación de la participación, probablemente "por correspondencia", de Edwards Bello en el movimiento dadaísta de Tristan Tzara.

Queda para futuras investigaciones preguntarse, desde el punto de vista de la exégesis textual, cómo los poemas publicados en revistas y recogidos luego en Metamorfosis se vinculan o no con la estética vanguardista canónica. Está, además, aún por descubrirse el rol que Jacques Edwards pudo haber tenido en la vanguardia local pensando, por ejemplo, en que su firma apareció, como adherente, junto a Huidobro, De Torre, los Borges y Manuel Maples Arce, en el manifiesto Rosa náutica de 1922. Respecto a la veracidad y alcance de su participación en los movimientos europeos, hasta aquí llega el aporte de este artículo.

\section{BIBLIOGRAFÍA}

Balmaceda Bello, Andrés. Bajo el polvo de los años: Recuerdos de juventud 1907-1917 y otros testimonios. Santiago, RIL editores, 2000.

Barrera López, José María. "Revisión de Grecia en la vanguardia". Monteagudo 7, 2002, pp. 45-56.

Benadava, Salvador. Faltaban solo unas horas... Aproximación a Joaquín Edwards Bello. Santiago, LOM Ediciones, 2006.

Bernabé, Mónica. Vida de artista: Bohemia y dandismo en Mariátegui, Valdelomar y Eguren (Lima, 1911-1922). Rosario, Beatriz Viterbo Editora, 2006.

Bonet, Juan Manuel. Diccionario de las vanguardias en España, 1907-1936. Madrid, Alianza Editorial, 1999.

Bourdieu, Pierre. Las reglas del arte: Génesis y estructura del campo literario. Barcelona, Editorial Anagrama, 2002.

Cannibale. 25 de abril de 1920.

Cansinos Assens, Rafael. La novela de un literato: (Hombres, ideas, escenas, efemérides, anécdotas...) 2. [1914-1921]. Madrid, Alianza Editorial, 2009.

Carvajal, Osvaldo. "Historia del texto y criterios editoriales". El roto. Edición crítica. Joaquín Edwards Bello. Santiago, Ediciones Universidad Alberto Hurtado, 2019, pp. 29-57.

"Nacimiento y formación de un cronista: Joaquín Edwards Bello y su incorporación al campo literario". Literatura y Lingüistica 43, 2021, pp. 171-202. 
Colombi, Beatriz. "Camino a la meca: escritores hispanoamericanos en París (1900-1920)". Historia de los intelectuales en América Latina. Carlos Altamirano (comp.), Buenos Aires, Katz, 2008, pp. 544-565.

De Torre, Guillermo. "Álbum de retratos de París y Madrid. Mis amigos y yo". Grecia. Septiembre de 1920 .

“El movimiento ultraísta español”. Cosmópolis. Noviembre de 1920, pp. 473-495. Historia de las literaturas de vanguardia. Madrid, Ediciones Guadarrama, 1965. Literaturas europeas de vanguardia. Sevilla, Editorial Renacimiento, 2001.

Del Vando-Villar, IsaAc. "Jacques Edwards". Grecia: Revista decenal de literatura. 20 de enero 1920, p. 5.

"París". Grecia: Revista decenal de literatura. 20 de diciembre de 1919, p. 18.

"Una carta de Vicente Huidobro". Grecia: Revista decenal de literatura. 31 de enero de 1920, pp. 1-2.

EDWARDS, JAC. “'Galería de espejos' (Autoversiones del francés)”. Grecia: Revista decenal de literatura. 20 de noviembre de 1920, pp. 7-9.

Edwards, JACques. "Carta a Tristan Tzara". Sin fecha. Fondo Tristan Tzara, Bibliothèque littéraire Jacques Doucet.

"Carta a Tristan Tzara". 6 de marzo de 1920. Fondo Tristan Tzara, Bibliothèque littéraire Jacques Doucet.

"Dios - N. ${ }^{\circ}$ 1-000 calle Pot de fer". Grecia: Revista decenal de literatura. 1 de junio de 1920 , p. 15.

"El aviador dada". Grecia: Revista decenal de literatura. 20 de enero de 1920, p. 5.

"El gato muy gordo". Grecia: Revista decenal de literatura. 15 de junio de 1920, p. 13.

"Espiral". Tableros. 15 de noviembre de 1921.

"La guerra". Grecia: Revista decenal de literatura. 1 de julio de 1920, p. 4.

Metamorfosis. Santiago, Imprenta Universitaria, 1921.

"París". Grecia: Revista decenal de literatura. 20 de diciembre de 1919, p. 18.

Sin título. Dada: $n^{\circ}$ 7. Marzo de 1920, p. 5.

Edwards Bello, Johquín. "Carta a Vicente Huidobro". 27 de diciembre de 1919. Fundación Vicente Huidobro.

“Carta a Vicente Huidobro". 12 de febrero de 1920. Fundación Vicente Huidobro.

“Carta a Vicente Huidobro”. 13 de febrero de 1920. Fundación Vicente Huidobro.

"Carta a Vicente Huidobro". Mayo de 1922. Fundación Vicente Huidobro.

Crónicas reunidas I 1921-1925. Santiago, Ediciones Universidad Diego Portales, 2008.

Epistolario sentimental. Santiago, Nascimento, 1969.

Hotel Hoddó. Santiago, Zig-Zag, 1966.

La cuna de Esmeraldo. Preludio de una novela chilena. París, Librairie Rosier, 1918. Memorias. Santiago, Leo Ediciones, 1983.

Recuerdos de un cuarto de siglo. Santiago, Zig-Zag, 1966. 
García Martín, José Luis (comp.). Poetas del Novecientos: entre el Modernismo y la Vanguardia: (Antología). Tomo I: De Fernando Fortún a Rafael Porlán. Madrid, Fundación Santander Central Hispano, 2001.

GonzÁlez, AníBAL. La crónica modernista hispanoamericana. Madrid, José Porrúa Turanzas, 1983.

González, Paulino y Rogelio Reyes. Los papeles perdidos de Isaac del Vando. Sevilla, Fundación El Monte y Real Academia Sevillana de Buenas Letras, 2003.

"Grecia. Revista decenal de literatura.- Director: Isaac del Vando-Villar.-Madrid". La Pluma. Agosto de 1920, p. 144.

Iwasaki, Fernando. RePublicanos: Cuando dejamos de Ser Realistas. Madrid, Algaba Ediciones, 2008.

Le Bon, Laurent. Dada. París, Editions du Centre Pompidou, 2005.

Martínez, JuAna. "Chilenos en Madrid. Joaquín Edwards Bello". Anales de literatura chilena 4, 2003, pp. 73-92.

Montes, Eugenio. "Gavilla lírica". Grecia: Revista decenal de literatura. 29 de febrero de 1920, p. 12.

Osuna, Rafael. Revistas de la vanguardia española. Sevilla, Editorial Renacimiento, 2005.

Quintana, EMiLIo. "El ultraísmo español en las revistas de la primera vanguardia belga: poesía y grabado en madera (Amberes-Bruselas, 1920-1922)". Revista de Historia de la Traducción. Universitat Autònoma de Barcelona (web), 10 de septiembre de 2012, consultado el 21 de noviembre de 2021, disponible en: http:/www.traduccionliteraria. org/1611/art/quintana.htm\#

“Quelques Présidents et Présidentes”. Dada: $n^{\circ}$ 6, Bulletin. Marzo de 1920.

Sarmiento, José Antonio. Las veladas ultraístas. Cuenca, Ediciones de la Universidad de Castilla-La Mancha, 2013.

Torres Rioseco, Arturo. Grandes novelistas de la América Hispana. Berkeley, University of California Press, 1949.

Vicuña, Manuel. La belle époque chilena: Alta sociedad y mujeres de elite en el cambio de siglo. Santiago, Editorial Sudamericana, 2001. 